\title{
Characterisation of cytolethal distending toxin (CDT) mutants of Campylobacter jejuni
}

\author{
D. PURDY, C. M. BUSWELL, A. E. HODGSON, K. McAlPINE, I. HENDERSON and S. A. LEACH \\ Centre for Applied Microbiology and Research, Salisbury, Wiltshire, SP4 OJG
}

\begin{abstract}
In order to assess the contribution of cytolethal distending toxin (CDT) to the toxigenicity and pathogenicity of Campylobacter jejuni, the $C$. jejuni 81-176 and $C$. jejuni NCTC 11168 CDTs were inactivated by insertional mutation of the $c d t B$ toxin subunit. Cell-free sonicates from isogenic $C$. jejuni 81-176 $\mathrm{cdtB}^{-}$strains were found to be greatly attenuated in HeLa cytotoxicity assays, whilst still retaining some toxigenicity. Sonicates from a $C$. jejuni NCTC 11168 cdtB $^{-}$strain produced no detectable cytotoxicity. When orally administered to adult severe combined immunodeficient (SCID) mice, C. jejuni $c d t B$ mutant strains were unaffected in enteric colonisation abilities but demonstrated impaired invasiveness into blood, spleen and liver tissues. These data suggest that CDT may be the principal toxin produced by this species and that some $C$. jejuni strains may generate additional toxigenic factor(s) distinct from CDT.
\end{abstract}

\section{Introduction}

Campylobacters are recognised to be among the principal causal agents of bacterial gastro-enteritis throughout the world [1]. Campylobacters have been demonstrated to produce a multi-subunit toxin, designated cytolethal distending toxin (CDT) [2]. This toxin is closely related to an emerging family of bacterial protein toxins produced by Escherichia coli [3-5], Shigella dysenteriae, S. boydii [6], Haemophilus ducreyi [7] and a more recently identified form from the peridontal pathogen Actinobacillus actinomycetemcomitans $[8,9]$.

CDT has been shown to affect F-actin assembly and cell division in Chinese hamster ovary (CHO) cells [10] resulting in a characteristic elongation and swelling of susceptible cells over a 72-96-h period [11], distinct from the effects of other extracellular bacterial toxins. Partially purified CDT preparations have also been demonstrated to induce a profuse watery diarrhoea in suckling mice [12]. Recently, the mode of action of the E. coli CDT has been identified

Received 14 Sept. 1999; accepted 25 Oct. 1999. Corresponding author: Dr D. Purdy (e-mail: des.purdy@, camr.org.uk). as affecting the cyclin regulatory unit, cdc2 protein kinase $[13,14]$. CDT acts by preventing dephosphorylation of the cyclin $\mathrm{B} 1 / \mathrm{cdc} 2$ protein kinase complex, which controls the entry of eukaryotic cells into mitosis [15]. This subsequently leads to a $\mathrm{G}_{2} / \mathrm{M}$ phase cell cycle block that results in swelling of affected cells and death 3-5 days after exposure.

An earlier report described an experimental infection model for campylobacters in adult immunodeficient mice [16]. Immunodeficient SCID-Beige mice infected with Campylobacter jejuni became rapidly and heavily colonised by campylobacters, thus providing a potential in-vivo model for assessment of the contribution of CDT to the pathophysiology of campylobacter infections.

Recently, a $H$. ducreyi $c d t C$ mutant has been characterised [17] and shown to be as virulent as wild-type bacteria in a rabbit model of experimental chancroid, despite producing no detectable CDT in tissue-culture assays. Given the paucity of knowledge and conflicting opinions concerning toxin production by campylobacters [18], the present study sought to investigate the contribution of CDT to the toxigenicity and pathogenicity of campylobacters, through the generation of toxin-deficient mutants. These mutants have been characterised for their ability to produce toxin active against HeLa and INT 407 cell lines and their ability to colonise and invade an adult SCID mouse model. 


\section{Materials and methods}

\section{Bacterial strains and plasmids}

C. jejuni NCTC 11168 [19], C. jejuni NCTC 12744 [20] and $C$. jejuni 81-176 [21] have been described previously. E. coli $\mathrm{DH} 5 \alpha$ and E. coli TOP10 were used as hosts in cloning experiments. Plasmids pCR2.1TOPO (Invitrogen) and pMTL22 [22] were used as cloning vectors.

\section{Media and growth conditions}

Campylobacters were grown routinely on either Columbia blood agar (CBA) containing defibrinated horse blood 10\%, cefoperazone-charcoal-desoxycholateamphotericin (CCDA) agar, Mueller-Hinton (MH) agar or $\mathrm{MH}$ broth (Unipath) under micro-aerobic conditions $\left(\mathrm{CO}_{2} 5 \%, \mathrm{O}_{2} 5 \%\right)$ in an ASSAB $\mathrm{CO}_{2}$ incubator (Don Whitley Scientific). E. coli was cultured at $37^{\circ} \mathrm{C}$ on yeast tryptone agar or in broth. When necessary to maintain plasmid selection, ampicillin was added to growth media at a final concentration of $50 \mathrm{mg} / \mathrm{L}$ and chloramphenicol $(\mathrm{Cm})$ was added at a final concentration of $20 \mathrm{mg} / \mathrm{L}$. All C. jejuni strains utilised in experimental procedures were low passaged isolates stored as frozen stocks at $-70^{\circ} \mathrm{C}$ on Microbank cryobeads (Prolab Diagnostics). Loss of virulence factors following prolonged passage or storage of strains has been suggested as one reason behind the often contradictory reports by different groups concerning toxin production by campylobacters [18] and, accordingly, experimental procedures were designed to minimise the in-vitro passage of isolates. All wild-type and mutant $C$. jejuni strains used in toxicity assays were passaged on fewer than four occasions. Mutations were generated in wild-type bacteria following a maximum of two passages to minimise the potential down-regulation of virulence genes and adaptation to growth on laboratory media. Campylobacters were recovered by plating on to $\mathrm{CBA}$ agar. Single colonies were then transferred to fresh CBA plates and incubated micro-aerobically for a further $24 \mathrm{~h}$ before use.

\section{DNA methods}

All restriction endonucleases, T4 DNA ligase and alkaline phosphatase were purchased from Roche Diagnostics and used according to the manufacturer's instructions. Plasmid DNA was isolated from E. coli by Qiaprep spin mini columns or Qiafilter maxi columns (Qiagen). All PCR cloning procedures with pCR2.1TOPO were performed according to the manufacturer's instructions (Invitrogen). Genomic DNA was prepared from campylobacters as described by Pitcher et al. [23]. Electrotransformations of campylobacters were done by the procedures described by Wassenaar et al. [20].
$P C R$

PCRs to amplify specific fragments from $C$. jejuni $c d t A B C$ genes were performed with primers based on C. jejuni 81-176 cdtABC sequence [2] as follows; primers P8 5' CTTATTCTAAAGGGGTAGCAGC3' and P9 5' CATATCAAGGTTTTTAATGC 3' were used to amplify a promoterless $c d t A B C$ operon from campylobacters; primers P5 5' GAATCCGTTGG CACTTGGAATTTGCAAGGC $3^{\prime}$ and P6 5' GGAT TCGTTAAAATCCCCTGCTATCATCCA 3' were used to amplify a region internal to the $c d t B$ gene from campylobacters. This DNA fragment was also used as a probe in later DNA-DNA hybridisations. All PCR reagents were supplied by Applied Biosystems. PCR reactions were carried out in $100-\mu \mathrm{l}$ volumes and contained $0.125 \mathrm{mM}$ (each) dATP, dCTP, dGTP and dTTP, $1 \times$ Amplitaq PCR buffer, 100 pmol of each primer, $0.1 \mu \mathrm{g}$ of template DNA and 2 units of Amplitaq DNA polymerase. Reactions were cycled with an MJ Research Hot Bonnet thermal cycler as follows: $94^{\circ} \mathrm{C}$ for $8 \mathrm{~min}$, followed by 30 cycles of $94^{\circ} \mathrm{C}$ for $30 \mathrm{~s}, 45^{\circ} \mathrm{C}$ for $30 \mathrm{~s}, 72^{\circ} \mathrm{C}$ for $2 \mathrm{~min}$ and a final extension step of $72^{\circ} \mathrm{C}$ for $8 \mathrm{~min}$. A PCR-amplified chloramphenicol resistance cassette was used in mutagenesis experiments and was generated as described by Yao et al. [24].

DNA-DNA hybridisations were performed with ECL non-radioactive gene detection systems (Amersham) according to the manufacturer's recommendations.

\section{Cell cytotoxicity assays}

HeLa cytotoxicity assays were done essentially as described by Pickett et al. [4], with slight modification. Briefly, campylobacters were grown micro-aerobically overnight on $\mathrm{MH}$ agar, containing chloramphenicol where appropriate. Cells were harvested, suspended in PBS and pelleted at $6000 \mathrm{~g}$. Pellets were resuspended in $1 \mathrm{ml}$ of PBS. The $\mathrm{A}_{590}$ of the resuspended cells was then determined. Cell suspensions were sonicated (Soniprep 150, MSE) for two 30-s bursts with a 30-s interval. After sonication, samples were centrifuged $(6000 \mathrm{~g})$ and supernates were filtered $(0.22 \mu \mathrm{m}$ pore size). CDT assays were performed with $\mathrm{HeLa}$ and INT407 cells grown in Eagle's minimal essential medium (EMEM) supplemented with fetal bovine serum $10 \%$. Microtitration plates (96-well) were seeded with $c .2 \times 10^{3}$ cells $(100 \mu \mathrm{l} /$ well $)$ and incubated for $18 \mathrm{~h}$ before the assay was performed. Toxin titres were determined by performing a two-fold dilution series of cell sonicates in EMEM medium; $100 \mu \mathrm{l}$ of each dilution were then applied to the HeLa and INT 407 cell microtitration plates. Titres were calculated by dividing the highest dilution to affect $50-75 \%$ of the cells in a well by the $\mathrm{A}_{590}$ of the resuspended C. jejuni cells. 


\section{C.B 17-SCID-Beige mouse intragastric challenge}

Wild-type and isogenic $C$. jejuni 81-176 cdtB- mutants were administered intragastrically to groups of adult C.B-17-SCID-Beige mice at doses of $10^{9} \mathrm{cfu} /$ mouse, according to the procedures described by Hodgson et al. [16]. Groups of five mice were then killed at 2, 6 and $24 \mathrm{~h}$ after challenge and blood, spleen, liver and faecal samples were removed and weighed. Control mice, uninfected with $C$. jejuni 81-176, were killed at equivalent time points. Viable counts were determined directly from blood samples plated on to CBA as described above. Liver and spleen samples were macerated in Ringer's solution in a Griffiths tube, before plating on to CCDA agar and CBA for viable counts. Remaining blood and macerated liver and spleen samples were incubated for $48 \mathrm{~h}$ in Brucella broth, before plating on to CCDA agar for detection of low levels of $C$. jejuni. Faecal samples were homogenised by stomaching, before serial dilution and plating on CCDA agar to determine intestinal colonisation levels in experimental animals. Histological examination of SCID mouse large intestine samples was done as described previously [16].

\section{Results}

\section{Generation of $C D T^{-}$mutants}

PCR amplification of a promoterless $c d t A B C$ operon was done with primers $\mathrm{P} 8$ and $\mathrm{P} 9$, based on the published nucleotide sequence from C. jejuni 81-176 [2]. A single fragment, corresponding in size to a promoterless $c d t A B C$ operon, was generated from PCR reactions with $C$. jejuni 12744 template DNA. This fragment was subsequently cloned into pCR2.1TOPO, generating the vector pDP32. Sequence analysis of insert DNA from pDP32 indicated the successful cloning of a promoterless copy of the $C$. jejuni $12744 c d t A B C$ operon. In order to generate a vector suitable for mutagenesis of the $C$. jejuni cdtABC operon, a PCR-amplified $P v u$ II flanked chloramphenicol resistance cassette [24] was cloned into the unique $H p a$ I site centrally located within the $C$. jejuni 12744 $c d t B$ gene. The resulting vector, pDP46, carried an insertionally inactivated $c d t B$ gene, but lacked sequences that would allow its extra-chromosomal maintenance in Campylobacter spp. Nucleotide sequencing results suggested that sufficient cross-strain homology was likely to exist for this vector to be utilised in mutagenesis experiments with a number of different $C$. jejuni strains. Restriction analysis indicated that the $\mathrm{Cm}$ resistance cassette was inserted in the opposite orientation to the promoterless $c d t A B C$ operon in pDP46 (data not shown).

Electroporation was used to transfer an insertionally inactivated $c d t B$ allelle to wild-type $C$. jejuni strains by homologous recombination. Cm-resistant transformants were initially screened by PCR with primers P5 and P6, which flank the insertion site within the $c d t B$ gene. All C. jejuni 11168 and C. jejuni 81-176 clones screened generated a single 1.2-kb PCR product, $c .800 \mathrm{bp}$ larger than wild-type bacteria, corresponding to the successful insertion of the $\mathrm{Cm}$ resistance cassette by double crossover. However, all C. jejuni $12744 \mathrm{Cm}$-resistant clones generated a single PCR amplification product of identical size to that from wild-type bacteria, indicating that a single crossing-over event may have taken place, or that $c d t B$ sequences harbouring the $\mathrm{Cm}$ resistance cassette may have illegitimately recombined back into the chromosome.

\section{DNA hybridisations}

To confirm the findings of initial PCR screens of putative $c d t B$ mutants, two oligonucleotide probes were used to determine the presence of the $\mathrm{Cm}$-resistance cassette within the $c d t B$ gene of $C$. jejuni 11168 and $C$. jejuni 81-176 and to confirm the presence or absence of plasmid sequences within the chromosome of $\mathrm{Cm}$ resistant strains. The non-radioactively labelled $c d t B$ probe consisted of a PCR-amplified fragment internal to the $C$. jejuni $11168 c d t B$ gene generated with the primer pair P5/P6. This hybridised to $B g l \mathrm{II} / E c o \mathrm{RV}-$ restricted DNA fragments, which appeared c. $800 \mathrm{bp}$ larger from $c d t B$ mutants than from wild-type $C$. jejuni 11168 and C. jejuni 81-176 strains (Fig. 1), corresponding to the successful insertion of the $\mathrm{Cm}$ cassette within the $c d t A B C$ operon. Both $C$. jejuni $c d t B$ mutants also demonstrated a decrease in fragment size hybridising to labelled $c d t B$ probe when digested with $B s c \mathrm{I}$, as a result of the presence of a $B s c$ I site within the Cmresistance cassette. Labelled pCR2.1 backbone failed to generate any signal under low stringency hybridisation conditions (data not shown) in duplicate blots, indicating that allelic exchange had occurred by double cross-over.

\section{HeLa cytotoxicity assays}

It has been shown previously that cloned $C$. jejuni $c d t A, c d t B$ and $c d t C$ genes are all required to produce active CDT in non-toxigenic E. coli $\mathrm{K} 12$ clones [2]. To assess the contribution of CDT to the overall cytotoxicity of $C$. jejuni, both mutant strains harbouring insertions within the $c d t B$ genes were assayed for cytotoxicity in HeLa cell assays. Serial dilutions of cell-free sonicates were applied to HeLa cell monolayers in 96-well microtitration plates. After incubation for $96 \mathrm{~h}$, cytopathic effects (CPEs) consistent with the activity of CDT were visible with both the wild-type $C$. jejuni strains assayed. Toxin titres of 4096 and 512 were generated by $C$. jejuni 81-176 and C. jejuni 11168 strains, respectively. However, in isogenic C. jejuni strains harbouring insertions in the $c d t B$ gene, toxin titres were either greatly reduced or completely abolished, with the $C$. jejuni 81-176 cdtB mutant generating a toxin titre of 8 and the $C$. jejuni 11168 $c d t B$ mutant generating no detectable cytotoxicity. This 


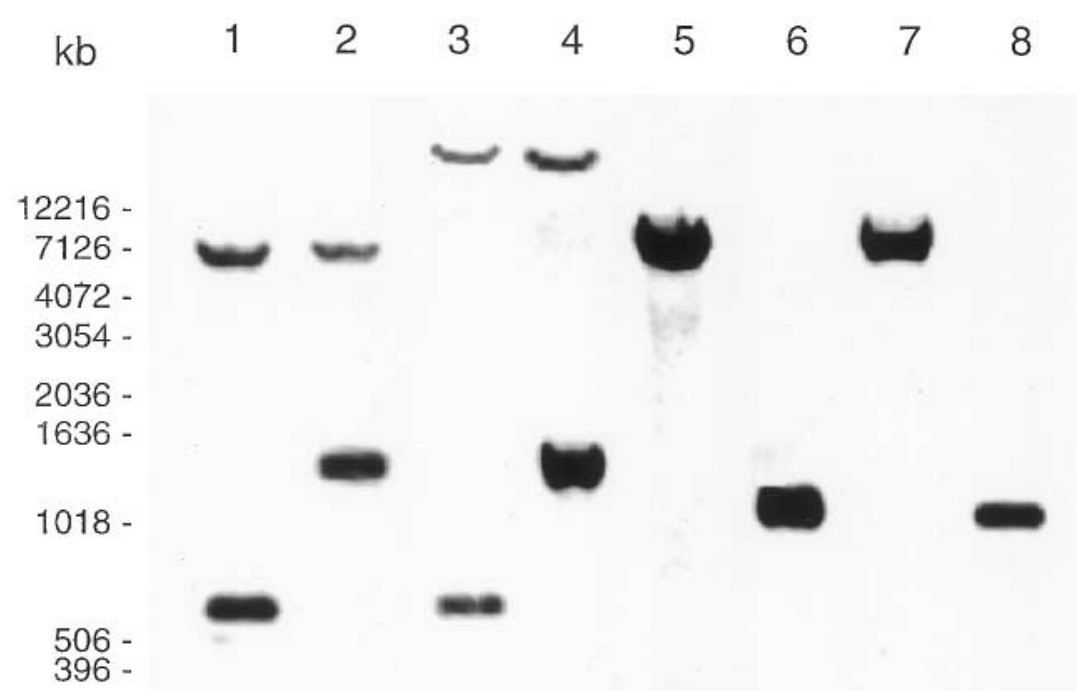

Fig. 1. Southern hybridisation of $C$. jejuni 11168 and $C$. jejuni 81-176 wild-type strains and $c d t B$ mutants. Lanes 1-4, BglII/EcoRV-digested chromosomal DNA from: 1, C. jejuni 11168 wild-type; 2, C. jejuni 11168 cdtB mutant; 3, C. jejuni 81-176 wild-type; 4, C. jejuni 8-176 cdtB mutant. Lanes 5-8, BscI-digested chromosomal DNA from: 5, $C$. jejuni 11168 wild-type; 6, C. jejuni 11168 cdtB mutant; 7, C. jejuni 81-176 wild-type; 8, C. jejuni 8-176 cdtB mutant.

absence of cytotoxicity in HeLa assays of the $C$. jejuni $11168 c d t B$ mutant leads to the speculation that CDT is the principal toxin produced by this strain under the growth conditions employed.

In contrast, $C$. jejuni $81-176 c d t B$ mutants still elicited cytopathic effects on the HeLa cells, albeit at greatly reduced titres. Typical morphology of HeLa cells was markedly different from CDT-induced CPE, indicating that another as yet undefined toxin may be active within these cells (Fig. 2). Cell-free sonicates imparted a distinctly elongated, spindle morphology on HeLa monolayers, but without the characteristic swelling of the cell associated with the action of CDT. Interestingly, this CPE is similar in nature to that generated following exposure of $\mathrm{CHO}$ cells to E. coli LT and may be associated with previous observations of enterotoxin-like activity generated by campylobacters $[25,26]$.

When identical comparative cytotoxicity assays were performed with INT407 cell monolayers, data generated from these assays corroborated those from the HeLa cell assays. However, INT407 cells consistently generated reduced toxin titres compared with HeLa cells (data not shown), typically of the order of 50$75 \%$. This is not surprising, as not all CDT-sensitive cell lines appear to display equivalent morphological effects [27] and may reflect potential differences in toxin receptor binding sites between the two cell lines. As such, HeLa cells may constitute a more useful choice of cell line for such toxicity assays.

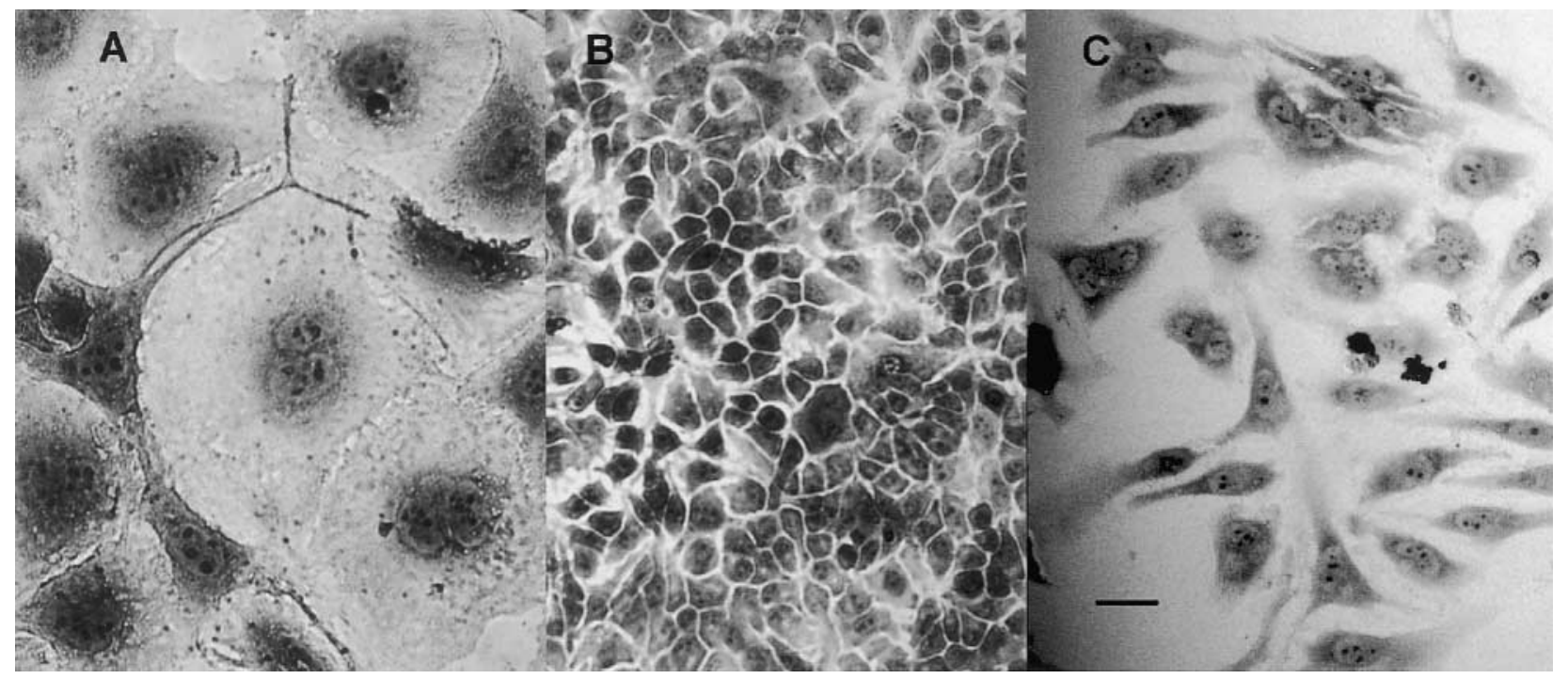

Fig. 2. Photomicrographs of Giemsa-stained HeLa cell monolayers: (A) treated with filtered C. jejuni 81-176 cell sonicates; (B) untreated control; (C) treated with filtered C. jejuni 81-176 cdtB mutant cell sonicates. Bar, $10 \mu \mathrm{m}$. 


\section{SCID mouse challenge}

Intragastric administration of $10^{9} \mathrm{cfu}$ of wild-type and isogenic $C$. jejuni 81-176 cdtB mutant strains to adult C.B-17-SCID-Beige mice was done to establish the contribution of CDT to campylobacter pathogenesis. These mice are homozygous for a recessive mutation that impairs early lymphocyte development and results in an absence of mature B- and T-cell lymphocytes $[16,28]$, subsequently rendering them more susceptible to enteric colonisation by campylobacters. Following intragastric inoculation of mice, blood obtained by cardiac puncture, liver and spleen samples were removed at 2, 6 and $24 \mathrm{~h}$ after challenge to assay for the presence of invasive campylobacters. Table 1 shows the first detected presence of $C$. jejuni 81-176 strains in mouse blood and tissues. At $2 \mathrm{~h}$ after challenge, wildtype bacteria were present in more spleen, liver and blood samples from experimental animals (8 of 15) than in samples from mice infected with isogenic $c d t B$ mutants (4 of 15). These results suggest that $C$. jejuni 81-176 $c d t B$ mutants invade SCID mouse tissues less readily than wild-type bacteria, most noticeably evidenced by the absence of $c d t B$ mutants in directly plated spleen samples, and suggest a possible role for CDT in campylobacter invasion.

Intestinal colonisation levels were monitored by direct plating of faecal samples and colony counts from mutant and wild-type $C$. jejuni 81-176 strains were indistinguishable (data not shown). As anticipated, during the comparatively short duration of the experiment, no SCID mice infected with wild-type or isogenic $C$. jejuni 81-176 cdtB mutants became ill, or displayed any obvious clinical symptoms relating to campylobacter infection. A previous study with CB-17SCID-Beige mice [16] demonstrated diarrhoeal symptoms and histopathological lesions typical of human campylobacteriosis only over more extended time periods. Microscopic examination of SCID mouse intestines 7 days after infection also failed to reveal any histopathological changes in mice infected with wild-type or mutant C. jejuni 81-176.

\section{Discussion}

This report indicates that CDT may be the principal toxin produced by both $C$. jejuni clinical isolates utilised in this study when cultured in vitro. Cell cytotoxicity assays indicated that $C$. jejuni $11168 \mathrm{cdt} B$ mutants produced no other toxin active against HeLa cells or INT407 cells under the experimental conditions used, whereas $C$. jejuni 81-176 $c d t B$ mutants appeared to retain a low level of toxic activity, apparently unrelated to the action of CDT. This weak residual toxicity on HeLa monolayers may account for an as yet uncharacterised toxic activity previously associated with campylobacters [18] and suggests that some, but not all, campylobacters may indeed produce more than one toxin. Previous studies, although unable to provide genetic data on toxic elements, have described various putative campylobacter toxins active on several different cell lines, ranging from Shiga-like toxin activity [29], to a number of different cytotoxins [30-32] enterotoxins [33,34] and a hepatotoxin [35]. Strain variation may account for some of these differences in toxin production, which may become clearer as new evidence of the genetic heterogeneity of the campylobacters emerges. Guerry et al. [36] have highlighted strain variations in the iron uptake systems of certain C. jejuni strains, suggestive of the fact that alternative iron acquisition systems may exist in these strains as a response to different pathogenesis strategies or occupation of different ecological niches. Similarly, less conserved metabolic functions, such as toxin production, may also differ significantly between strains. It is also perhaps unfortunate that the $C$. jejuni 11168 strain, for which complete nucleotide sequence is now available [www.sanger.ac.uk/Projects/C_jejuni/], generated no additional toxigenicity following insertional inactivation of its $c d t A B C$ operon.

The widespread presence of genes encoding CDT amongst members of the Campylobacter genus was recently demonstrated by Eyigor et al. [37], indicating that CDT may be intimately involved in successful colonisation processes and in the ability of the

Table 1. Summary of $C$. jejuni 81-176 wild-type and $c d t B$ mutant isolation from CB-17-SCID-Beige mice

\begin{tabular}{|c|c|c|c|}
\hline \multirow{2}{*}{$\begin{array}{l}\text { Time after } \\
\text { challenge (h) }\end{array}$} & \multirow[b]{2}{*}{ Sample type } & \multicolumn{2}{|c|}{ Number of animals (out of 5 tested) with positive tissues } \\
\hline & & C. jejuni 81-176 wild-type & C. jejuni 81-176 cdtB mutant \\
\hline \multirow[t]{3}{*}{2} & Spleen & $3 \mathrm{D}$ & $1 \mathrm{E}$ \\
\hline & Liver & $4 \mathrm{D}$ & $3 \mathrm{D}$ \\
\hline & Blood & $1 \mathrm{D}$ & 0 \\
\hline \multirow[t]{3}{*}{6} & Spleen & 0 & 0 \\
\hline & Liver & $3 \mathrm{D}+1 \mathrm{E}$ & $3 \mathrm{D}+1 \mathrm{E}$ \\
\hline & Blood & 0 & 0 \\
\hline \multirow[t]{3}{*}{24} & Spleen & $1 \mathrm{D}$ & 0 \\
\hline & Liver & 0 & $1 \mathrm{D}$ \\
\hline & Blood & 0 & 0 \\
\hline
\end{tabular}

$\mathrm{D}$, detected by direct plating; E, detected by enrichment only. 
organism to cause disease in man. Inactivation of $c d t B$ subunits in $C$. jejuni strains leads to a decrease in the ability of bacteria to invade C.B-17-SCID-Beige mouse tissues, further implying a potential role for this toxin in campylobacter pathogenesis. Given the plasticity of the campylobacter genome, the ubiquitous presence of the $c d t A B C$ operon amongst campylobacters is suggestive of the need for toxin production for pathogenesis in a suitable host. Coupled with the observation that $C$. jejuni, the principal human pathogen of the genus, also appears to elicit more CDT than other Campylobacter species $[2,14]$ this provides further evidence for involvement of CDT in campylobacter pathophysiology.

Although none of the C.B-17-SCID-Beige mice displayed overt signs of clinical illness in terms of diarrhoea or changes in gut histopathology during this study, the experimental period used was much shorter than that in previous studies [16]. Suckling mice challenged intragastrically with $E$. coli culture supernates expressing cloned $S$. dysenteriae $c d t A B C$ genes and partially purified toxin have previously developed CDT-induced watery diarrhoea [12]. It is unclear at present whether this difference in susceptibility to the toxin is related to the age and strain of mice, if toxin expression in the SCID mouse gut is reduced, or if it represents functional differences between the $C$. jejuni and $S$. dysenteriae CDTs.

Some correlation also appears to exist between the numbers of invading $C$. jejuni and the transcriptional activity of the $c d t$ promoter in vitro. Reporter gene fusions to the $c d t$ promoter demonstrate maximum activity within $2 \mathrm{~h}$ of inoculation of batch cultures, followed by a rapid decline in promoter activity (unpublished observations). Wild-type C. jejuni 81176 invaded the tissues and blood of experimental animals more frequently and in greater numbers than the $c d t B$ mutants $2 \mathrm{~h}$ after challenge, coinciding with the potential maximum transcriptional activity of the $c d t$ promoter. At this time point, wild-type bacteria were detected by direct plating in three positive spleen samples, whereas $\mathrm{CDT}^{-}$mutants were only present following enrichment in the spleen of a single animal, indicating that inactivation of CDT may contribute towards reduced invasiveness. The fact that the mutant C. jejuni strain was still invasive reflects the multifactorial nature of invasion in this species [38].

These studies have demonstrated a potential relationship between the production of CDT and the invasive abilities of $C$. jejuni strains in a SCID mouse model. A wild-type strain consistently generated high toxin titres and was more successful in invading mouse tissues; in contrast, isogenic $c d t B$ mutants failed to produce detectable toxin in the case of the $C$. jejuni 11168 mutant, or at greatly reduced titres in the case of the $C$. jejuni 81-176 mutant, indicating successful inactivation of CDT. More work will be necessary to unravel the complex nature of campylobacter pathogenesis, particularly in relation to clearly defining determinants of invasion and the clarification of the role of other toxic factors in this process.

We would like to thank Dr Diane Newell for the generous gift of $C$. jejuni 81-176, Dr Graham Hall for histopathological analysis of intestinal sections and the Department of Health, London for funding this work.

\section{References}

1. Tauxe RV. Epidemiology of Campylobacter jejuni infections in the United States and other industrialised nations. In: Nachamkin I, Blaser MJ, Tompkins LS (eds) Campylobacter jejuni: current status and future trends. Washington DC, American Society for Microbiology. 1992: 9-19.

2. Pickett CL, Pesci EC, Cottle DL, Russell G, Erdem AN, Zeytin H. Prevalence of cytolethal distending toxin production in Campylobacter jejuni and relatedness of Campylobacter sp. $c d t B$ genes. Infect Immun 1996; 64: 2070-2078.

3. Scott DA, Kaper JB. Cloning and sequencing of the genes encoding Escherichia coli cytolethal distending toxin. Infect Immun 1994; 62: 244-251.

4. Pickett CL, Cottle DL, Pesci EC, Bikah G. Cloning, sequencing, and expression of the Escherichia coli cytolethal distending toxin genes. Infect Immun 1994; 62: 1046-1051.

5. Pérès SY, Marchès $\mathrm{O}$, Daigle $\mathrm{F}$ et al. A new cytolethal distending toxin (CDT) from Escherichia coli producing CNF2 blocks HeLa cell division in $\mathrm{G} 2 / \mathrm{M}$ phase. Mol Microbiol 1997; 24: 1095-1107.

6. Johnson WM, Lior H. Production of Shiga toxin and a cytolethal distending toxin (CLDT) by serogroups of Shigella spp. FEMS Microbiol Lett 1987; 48: 235-238.

7. Cope LD, Lumbley S, Latimer JL et al. A diffusible cytotoxin from Haemophilus ducreyi. Proc Natl Acad Sci USA 1997; 94: 4056-4061.

8. Shenker BJ, McKay T, Datar S, Miller M, Chowhan R, Demuth D. Actinobacillus actinomycetemcomitans immunosuppressive protein is a member of the family of cytolethal distending toxins capable of causing a $\mathrm{G}_{2}$ arrest in human $\mathrm{T}$ cells. J Immunol 1999; 162: 4773-4780.

9. Mayer MPA, Bueno LC, Hansen EJ, DiRienzo JM. Identification of a cytolethal distending toxin gene locus and features of a virulence-associated region in Actinobacillus actinomycetemcomitans. Infect Immun 1999; 67: 1227-1237.

10. Aragon V, Chao K, Dreyfus LA. Effect of cytolethal distending toxin on F-actin assembly and cell division in Chinese hamster ovary cells. Infect Immun 1997; 65: 3774-3780.

11. Johnson WM, Lior H. A new heat-labile cytolethal distending toxin (CLDT) produced by Campylobacter spp. Microb Pathog 1988; 4: 115-126.

12. Okuda J, Fukumoto M, Takeda Y, Nishibuchi M. Examination of diarrheagenicity of cytolethal distending toxin: Suckling mouse response to the products of the $c d t A B C$ genes of Shigella dysenteriae. Infect Immun 1997; 65: 428-433.

13. Comayras C, Tasca C, Pérès SY, Ducommun B, Oswald E, De Rycke J. Escherichia coli cytolethal distending toxin blocks the $\mathrm{HeLa}$ cell cycle at the $\mathrm{G}_{2} / \mathrm{M}$ transition by preventing cdc2 protein kinase dephosphorylation and activation. Infect Immun 1997; 65: 5088-5095.

14. Whitehouse CA, Balbo PB, Pesci EC, Cottle DL, Mirabito PM, Pickett CL. Campylobacter jejuni cytolethal distending toxin causes a $\mathrm{G}_{2}$-phase cell cycle block. Infect Immun 1998; 66: 1934-1940.

15. Dunphy WG. The decision to enter mitosis. Trends Cell Biol 1994; 4: 202-207.

16. Hodgson AE, McBride BW, Hudson MJ, Hall G, Leach SA. Experimental campylobacter infection and diarrhoea in immunodeficient mice. J Med Microbiol 1998; 47: 799-809.

17. Stevens MK, Latimer JL, Lumbley S et al. Characterization of a Haemophilus ducreyi mutant deficient in expression of cytolethal distending toxin. Infect Immun 1999; 67: 3900-3908.

18. Wassenaar TM. Toxin production by Campylobacter spp. Clin Microbiol Rev 1997; 10: 466-476. 
19. Karlyshev AV, Henderson J, Ketley JM, Wren BW. An improved physical and genetic map of Campylobacter jejuni NCTC 11168 (UA580). Microbiology 1998; 144: 503-508.

20. Wassenaar TM, Fry BN, van der Zeijst BAM. Genetic manipulation of Campylobacter: evaluation of natural transformation and electro-transformation. Gene 1993; 132: 131-135.

21. Black RE, Levine MM, Clements ML, Hughs TP, Blaser MJ. Experimental Campylobacter jejuni infection in humans. J Infect Dis 1988; 157: 472-479.

22. Chambers SP, Prior SE, Barstow DA, Minton NP. The pMTL nic $^{-}$cloning vectors. I. Improved pUC polylinker regions to facilitate use of sonicated DNA for nucleotide sequencing. Gene 1988; 68: 139-149.

23. Pitcher DG, Saunders NA, Owen RJ. Rapid extraction of bacterial genomic DNA with guanidium thiocyanate. Lett Appl Microbiol 1989; 8: 151-156.

24. Yao R, Alm RA, Trust TJ, Guerry P. Construction of new Campylobacter cloning vectors and a new mutational cat cassette. Gene 1993; 130: 127-130.

25. Klipstein FA, Engert RF. Properties of crude Campylobacter jejuni heat-labile enterotoxin. Infect Immun 1984; 45: 314-319.

26. Johnson WM, Lior H. Toxins produced by Campylobacter jejuni and Campylobacter coli. Lancet 1984; 1: 229-230.

27. Pickett CL, Whitehouse CA. The cytolethal distending toxin family. Trends Microbiol 1999; 7: 292-297.

28. Bosma MJ, Carroll AM. The SCID mouse mutant: definition, characterization and potential uses. Annu Rev Immunol 1991; 9: $323-350$.

29. Moore MA, Blaser MJ, Perez-Perez GI, O’Brien AD.
Production of a shiga-like cytotoxin by Campylobacter. Microb Pathog 1988; 4: 455-462.

30. Pang T, Wong PY, Puthucheary SD, Sihotang K, Chang WK In-vivo and in-vitro studies of a cytotoxin from Campylobacter jejuni. J Med Microbiol 1987; 23: 193-198.

31. Guerrant RL, Wanke CA, Pennie RA, Barrett LJ, Lima AAM, O'Brien AD. Production of a unique cytotoxin by Campylobacter jejuni. Infect Immun 1987; 55: 2526-2530.

32. Johnson WM, Lior H. Cytotoxic and cytotonic factors produced by Campylobacter jejuni, Campylobacter coli, and Campylobacter laridis. J Clin Microbiol 1986; 24: 275-281.

33. Ruiz-Palacios GM, Torres J, Torres NI, Escamilla E, RuizPalacios BR, Tamayo J. Cholera-like enterotoxin produced by Campylobacter jejuni. Characterisation and clinical significance. Lancet 1983; 2: 250-253.

34. McCardell BA, Madden JM, Lee EC. Production of choleralike toxin by Campylobacter jejuni/coli. Lancet 1984; 1: 448-449.

35. Kita E, Oku D, Hammuro A et al. Hepatotoxic activity of Campylobacter jejuni. J Med Microbiol 1990; 33: 171-182.

36. Guerry P, Perez-Casal J, Yao R, McVeigh A, Trust TJ. A genetic locus involved in iron utilization unique to some Campylobacter strains. $J$ Bacteriol 1997; 179: 3997-4002.

37. Eyigor A, Dawson KA, Langlois BE, Pickett CL. Cytolethal distending toxin genes in Campylobacter jejuni and Campylobacter coli isolates: Detection and analysis by PCR. J Clin Microbiol 1999; 37: 1646-1650.

38. Ketley JM. Pathogenesis of enteric infection by Campylobacter. Microbiology 1997; 143: 5-21. 